\title{
The Impact of Meaningful High School Computer Science Experiences in the Chicago Public Schools
}

\author{
Lucia Dettori \\ DePaul University \\ Ronald I. Greenberg \\ Loyola University Chicago, Rgreen@luc.edu \\ Steven McGee \\ The Learning Partnership \\ Dale Reed \\ University of Illinois at Chicago \\ Follow this and additional works at: https://ecommons.luc.edu/cs_facpubs \\ Part of the Computer Sciences Commons, Curriculum and Instruction Commons, Science and \\ Mathematics Education Commons, Secondary Education Commons, and the Teacher Education and \\ Professional Development Commons
}

Author Manuscript

This is a pre-publication author manuscript of the final, published article.

\section{Recommended Citation}

Lucia Dettori, Ronald I. Greenberg, Steven McGee, and Dale Reed. The impact of meaningful high school computer science experiences in the Chicago Public Schools. In Proceedings of 2015 Research in Equity and Sustained Participation in Engineering, Computing, and Technology (RESPECT), August 2015.

This Article is brought to you for free and open access by the Faculty Publications and Other Works by Department at Loyola eCommons. It has been accepted for inclusion in Computer Science: Faculty Publications and Other Works by an authorized administrator of Loyola eCommons. For more information, please contact ecommons@luc.edu.

\section{(c) $(1) \ominus$}

This work is licensed under a Creative Commons Attribution-Noncommercial-No Derivative Works 3.0 License. 


\title{
The Impact of Meaningful High School Computer Science Experiences in the Chicago Public Schools
}

\author{
Lucia Dettori*, Ronald I. Greenberg ${ }^{\dagger}$, Steven McGee ${ }^{\ddagger}$, and Dale Reed ${ }^{\S}$ \\ ${ }^{*}$ School of Computing, DePaul University, Chicago, Illinois 60604 \\ Email: lucia@cdm.depaul.edu \\ ${ }^{\dagger}$ Department of Computer Science, Loyola University, Chicago, Illinois 60611 \\ Email: rig@cs.luc.edu \\ ${ }^{\ddagger}$ The Learning Partnership, Western Springs, Illinois 60558 \\ Email: mcgee@lponline.net \\ $\S$ Department of Computer Science, University of Illinois at Chicago, Chicago, Illinois 60607 \\ Email: reed@uic.edu
}

\begin{abstract}
We report on initial outcomes of the Taste of Computing project, under which a meaningful computer science course has been initiated in many high schools of the Chicago Public Schools system. Surveys of students have shown that they attribute high value to the course and have experienced increases in their understanding and interest regarding the computing field. Data was also collected from teachers participating in professional development regarding their preparation and confidence in teaching the new course. We report on the strengths of various survey responses and their relationships, and we compare student responses by race and gender. The data provide a good basis for exploring the impact of meaningful computer science instruction on students from groups underrepresented in computing; of several hundred students surveyed, nearly half were female, and over half were Hispanic or African-American.
\end{abstract}

\section{INTRODUCTION}

According to Bureau of Labor Statistics projections, the computer and mathematical occupations group is the fifth fastest growing of their 22 major occupational groups, ranking only behind categories with substantially lower mean annual wages [1], [2]. The computer and mathematical group is third highest in income, with mean annual wages about three times as large as the category that led in growth projections for number of jobs. Additional points noted by BLS are that seven of the 10 largest STEM occupations were related to computers, and 93 of the 100 STEM occupations had mean wages significantly above the all-occupations average [2]. Meanwhile, the percentage of jobs in the computer/mathematical group occupied by Women, African-Americans, and Hispanics is only $25.6 \%, 8.3 \%$, and $6.6 \%$, respectively [3] (in contrast to representation in the overall population at $50.8 \%, 12.6 \%$, and $16.3 \%$, respectively [4]). Indications of this impending employment/economic disparity can also be seen in data showing the representation of these demographic groups among computing bachelor's degree recipients included in the latest Taulbee Survey report, $15 \%, 4 \%$, and $8 \%$, respectively $[5$, Tables B2,B3]. This report shows that despite overall growth in computer science enrollments, the largest underrepresented demographic groups are showing only small improvement at $21 \%, 5.6 \%$, and $9.6 \%$ [5, Table B8] in figures for current computing enrollments.

978-1-5090-0151-4/15/\$31.00 (c)2015 IEEE
The disparity in education outcomes at the college level is in turn connected to differential educational outcomes at the high school level [6], [7], [8]. Therefore, providing equitable access to high school computer science experiences seems like a possible avenue for enhancing long-term equity in economic opportunity in computer science. This paper investigates the impact of introducing a new computing course experience to high school students in the nation's third largest school district, specifically Chicago Public Schools (CPS).

\section{TheORETICAL FrameWORK}

Differential participation in high school computer science courses is rooted in a variety of individual and social causes. In this paper, we focus on low quality of high school computer science classes as a root cause that is prevalent in lowincome urban school systems. In many of those settings, instruction remains focused on basic computing literacy and use of computer applications. Where instruction is taken to a higher level, it has tended to be primarily focused on abstract fundamentals of computer programming; many students have difficulty relating to this approach, and computing in high schools and colleges has tended to appeal most strongly to Caucasian boys [9]. In addition, school technology experiences for students in low-income neighborhoods tend to be very scripted and lack opportunities for engaging in collaborative inquiry [10], [11]. These general results have been replicated by an internal survey of students in computing classes in CPS predating introduction of the new course. The students tended to be disappointed with the nature of the computer science content in the classes. In addition, the students felt that the teachers lacked the qualifications to teach computer science since the teachers could not present the concepts in a way that was meaningful to the students.

Outside of school, technology use by youth of all races and genders tends to center around making social connections and working on practical problems [12]. Reorienting computer science instruction around problem-solving experiences that are meaningful to students has the potential to increase the appeal of computer science content [13], [14]. For example, this type of change to introductory courses at Carnegie Mellon was part of a successful program to increase the representation of women in computer science [9]. 
At the high school level, researchers at UCLA have developed a high school introductory computer science curriculum, called Exploring Computer Science (ECS), that addresses the results of this prior research through a set of culturally-relevant and equity-oriented activities that focus on engaging students in computer science problem-solving [15]. The ECS program has had promising results in Los Angeles schools [16].

In this paper, we explore the impact of implementing ECS in a growing number of high schools in CPS. We focused on the construct of inspiration [17] as the theoretical lens for evaluating student outcomes. Inspiration is comprised of three main constructs: cognition, emotional outlook, and career interest. Increasing career interest and positive emotional outlook towards the field without increases in cognitive development leads to disappointment. On the other hand, the development of cognitive aptitude without career interest leads to other career choices. All three constructs of inspiration need to point in the same direction for students to be inspired to pursue a given career. We have begun to work with researchers from SRI with respect to evaluating computational thinking knowledge, skill, and ability outcomes [18]; meanwhile, we report here on outcomes relating to interest and motivation.

\section{METHOD}

This paper focuses on the implementation of ECS in the 2012-13 school year by seven teachers who administered a student end-of-course survey to 349 students. Almost half the students were girls $(48 \%)$, and more than half were Hispanic $(36 \%)$ or African-American (19\%).

The teachers whose students we surveyed were among the participants in a multi-year ECS professional development program conducted by university and high school teachers. Fifty-eight of these teachers responded to one or more questions on a background survey; they represented a relatively experienced group of urban educators with an average of 10 years of teaching experience and an average of almost 7 years of experience specifically teaching computing courses. Most of the teachers have primary certifications in business $(59 \%)$ or computer science $(53 \%)$ as well as experience working in the field of computer science (10.8 years). Most of the participants had taken 3 or more college-level computer science classes. As a group, they had been active participants in computer science professional development over the previous three years. Less than half reported having used Exploring Computer Science prior to Summer 2012, but most anticipated using the curriculum during the 2012-13 school year.

The surveyed teachers felt strongly that the professional development program was effective, as has also been reported by teachers participating in professional development in Los Angeles [19], which model was closely followed in Chicago. The teachers reported a significant increase in their confidence in using the equity and inquiry strategies that underlie the ECS curriculum. During the 2012-13 school year, 42 teachers taught Exploring Computer Science to over 2600 CPS students in 27 schools. Of the 34 teachers who reported on their implementation, over three-fourths of the teachers reported completing the first four units of the ECS curriculum. The extent to which teachers felt that the professional development was effective predicted the number of units that the teachers completed, but did not predict teachers' feelings of success. As indicated above, this study focuses on responses of students in ECS classes taught by the seven teachers who administered surveys to their classes. (The limited number of teachers was due to the complexity of obtaining IRB approval and student/parent consents.)

\section{INSTRUMENT}

At the end of the ECS course, student surveys [20] asked for background information (gender, year in school, race, and math grades), level of interest in taking another computer science course and pursuing a major in various subjects in college, and responses on a five-level Likert scale to several items that were combined into measures of awareness of the computing field and its diversity $(\alpha=0.84)^{1}$, perceived value of the ECS course $(\alpha=0.74)$, utility of computer science as a field $(\alpha=0.72)$, and persistence in solving computer science problems $(\alpha=0.63)$.

\section{RESUlts}

Overall, students rated the perceived value of the class quite high (3.9 out of 5). There were no gender or racial/ethnic differences in students' perceived value of the class. The students' open-ended comments about the class seem to reinforce the high rating of perceived value. Overwhelmingly, the students felt that the teacher made the class enjoyable. Equity is one of the three pillars of ECS. The fact that the vast majority of students felt a connection with their teacher suggests that the teachers were inclusive of the majority of the students in the class. In addition to equity, the vast majority of students indicated that they enjoyed the challenge, interactivity, and creativity of the class activities, all of which are hallmarks of an inquiry-based classroom setting, which is the second pillar of ECS. (The third pillar is content, in which the evaluation of student achievement is at a more incipient stage [18].)

Students also gave very strong responses regarding their interest in pursuing further studies in computer science. $74 \%$ of students surveyed indicated increased interest in taking another computer science course as well as in majoring in computer science in college (split about evenly between "increased a little" and "increased a lot"). When asked about interest in majoring in science, engineering, and mathematics, there was still somewhat of an increase of interest, but the neutral responses were two to three times as common as for computer science. This both strengthens the apparent significance of the computer science results and suggests that the curriculum has some success in demonstrating the interconnectedness between computer science and other fields.

We conducted a series of multiple regression analyses to identify which factors influence students' interest in pursuing further studies in computer science as well as their persistence in solving computer science problems. Core to the analyses is the extent to which students' course experience as measured by the perceived value of the course increased student interest in pursuing further computer science studies. The following list

\footnotetext{
${ }^{1}$ The symbol $\alpha$ stands for the Cronbach reliability, a measure of the internal consistency of items combined to form a scale.
} 


\section{Exploring Computer Science 2012-13 Results}

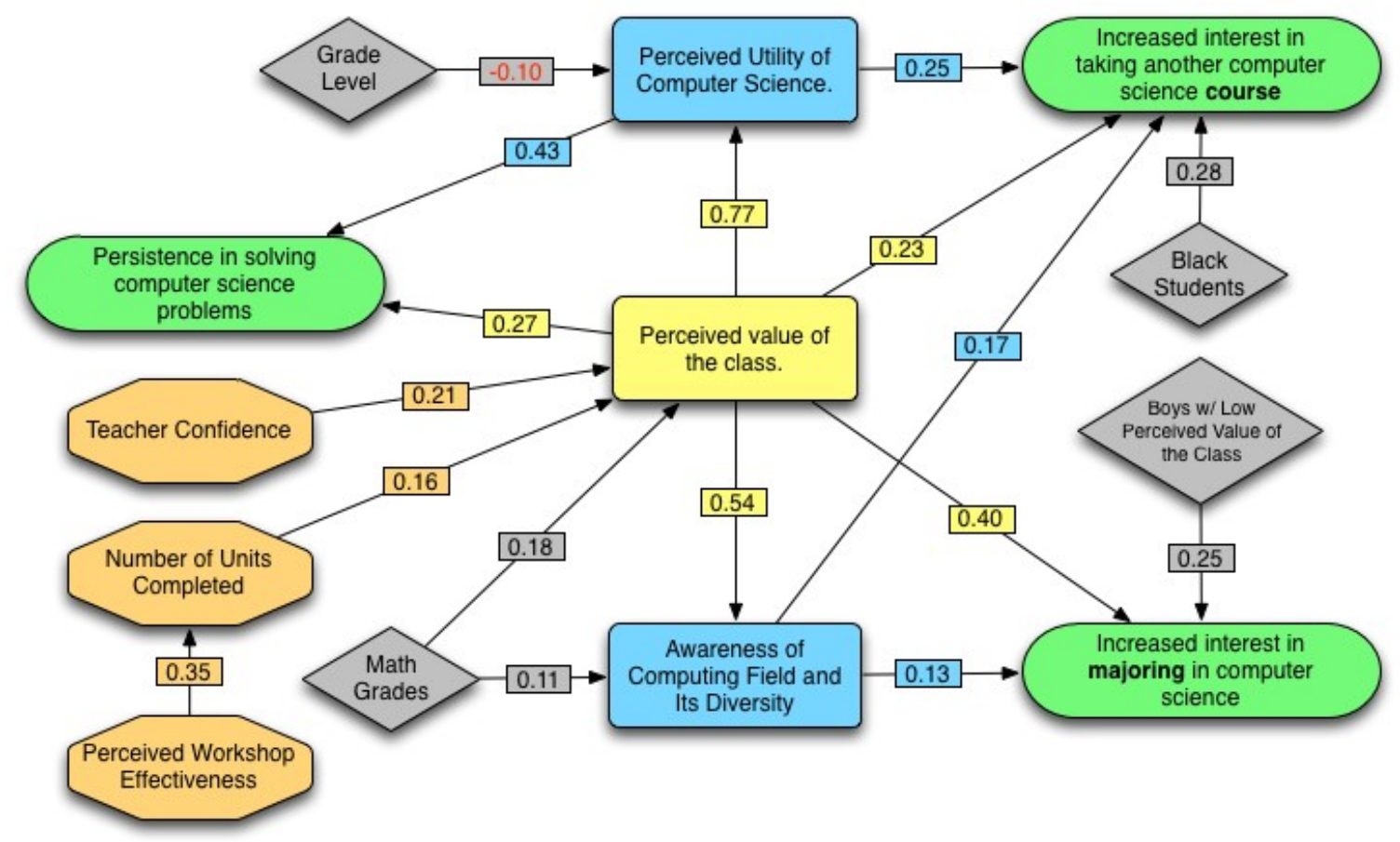

Fig. 1. Summary of multiple regression analyses of 2012-13 student survey responses

describes the multiple regressions that were conducted. Figure 1 provides a graphical summary of the multiple regression analyses.

- After controlling for gender, race, prior math grades, and grade level, the extent to which students increased their interest in taking another computer science course was significantly predicted by the students' perceived value of the class, their perceived utility of computer science, and their awareness of the computing field and its diversity $\left(R^{2}=34 \%\right)$. In addition, African-American students were more likely to increase their interest in taking another computer science course than other students $(\beta=0.28)^{2}$. There were no gender differences.

- After controlling for gender, race, prior math grades, and grade level, the extent to which students increased their interest in majoring in computer science in college was significantly predicted by the students' perceived value of the class and their awareness of the computing field and its diversity, but not their perceived utility of computer science $\left(R^{2}=25 \%\right)$. In addition, there was an interaction effect of gender by perceived value of the class. There were no gender differences among students who rated the value of the course as high. For students who rated the value of the class as low, girls were more likely to decrease

\footnotetext{
${ }^{2}$ The symbol $\beta$ is the standardized beta coefficient and represents the relationship strength on a scale of 0 to 1 .
}

their interest than boys $(\beta=0.24)$.

- After controlling for gender, race, prior math grades, and grade level, students' persistence in solving computer science problems was significantly predicted by the students' perceived value of the class and their perceived utility of computer science $\left(R^{2}=46 \%\right)$.

- After controlling for gender, race, prior math grades, and grade level, the students' course experience predicted the students' perceived utility of computer science $\left(R^{2}=61 \%\right)$ as well as students' awareness of the computing field and its diversity $\left(R^{2}=33 \%\right)$. In addition, the perceived utility of computer science was negatively correlated with year in school such that younger students reported higher perceived utility than older students. Also, students with higher self-reported math grades reported higher levels of awareness of the computing field and its diversity.

- There was one student-level and two teacher-level characteristics that predicted students' perceived value of the course $\left(R^{2}=11 \%\right)$. Students with higher selfreported math grades perceived higher value of the class. At the teacher level, the more ECS units a teacher completed and the more confident teachers were predicted higher levels of students' perceived value of the class. 


\section{SIGNIFICANCE}

There are two policy related findings. First, for the majority of students who had a positive class experience, there were no gender or racial/ethnic differences in the level of increased interest in taking another computer science class and majoring in computer science, with the exception that African-American students had a greater increase in interest in taking another computer science class. It would be important for counselors to capitalize on this across-the-board increased interest in taking another class by ensuring that this interest translates into registrations for subsequent computer science courses. Second, after controlling for perceived value of the class, the perceived utility of computer science decreased for older students. This finding reinforces the district's Career and Technical Education office recommendation that Exploring Computer Science be taught as a sophomore course. Starting early capitalizes on the higher feelings of utility during sophomore year and creates a trajectory for students to take AP computer science as seniors.

Overall, the students' free response comments about the ECS class suggest that teachers implemented the class in a way that was meaningful to the students. This meaningfulness translated into overall high perceived value of the class and increased interest in further pursuing computer science classes. If students continue taking computer science classes in high school, it increases their chances of success in college computer science classes, which can open the door to equitable access to computer science careers.

\section{ACKNOWLEDGMENTS}

This work was supported in part by National Science Foundation grants CNS-1138515 and CNS-1138417.

\section{REFERENCES}

[1] United States Department of Labor Bureau of Labor Statistics, "Table 6. employment by major occupational group, 2012 and projected 2022,' http://www.bls.gov/news.release/ecopro.t06.htm, Dec. 2013, retrieved $5 / 13 / 2015$.

[2] - "Occupational employment and wages news release," http://www. bls.gov/news.release/ocwage.htm, Mar. 2015, retrieved 5/13/2015.

[3] — " "11. employed persons by detailed occupation, sex, race, and hispanic or latino ethnicity," http://www.bls.gov/cps/cpsaat11.htm, Feb. 2015, retrieved 5/13/2015.

[4] United States Census Bureau, "Profile of general demographic and housing characteristics: 2010," http://factfinder.census.gov/ faces/tableservices/jsp/pages/productview.xhtml?PID=DEC_10_DP_ DPDP1\&scr=pt, 2010, retrieved 5/13/2015.

[5] S. Zweben and B. Bizot, "2014 Taulbee survey: Relentless growth in undergraduate CS enrollment; doctoral degree production remains strong, but no new record," Computing Research News, vol. 27, no. 5, pp. 2-51, 2015.

[6] J. Gal-Ezer and C. Stephenson, "The current state of computer science in U.S. high schools: A report from two national surveys," Journal for Computing Teachers, Spring 2009. [Online]. Available: http://csta.acm. org/Research/sub/Projects/ResearchFiles/StateofCSEDHighSchool.pdf
[7] H. Taylor and L. Mounfield, "Exploration of the relationship between prior computing experience and gender on success in college computer science," Educational Computing Research, vol. 11, no. 4, pp. 291-306, 1994. [Online]. Available: http://dx.doi.org/10.2190/ 4U0A-36XP-EU5K-H4KV

[8] B. C. Wilson, "A study of factors promoting success in computer science," Computer Science Education, vol. 12, no. 1-2, pp. 141-164, 2002. [Online]. Available: http://dx.doi.org/10.1076/csed.12.1.141.8211

[9] J. Margolis and A. Fisher, Unlocking the Clubhouse: Women in Computing. MIT Press, 2002.

[10] J. Margolis, R. Estrella, J. Goode, J. J. Holme, and K. Nao, Stuck in the Shallow End: Education, Race, and Computing. MIT Press, 2008.

[11] J. Reich, R. Murnane, and J. Willett, "The state of wiki usage in U.S K-12 schools: Leveraging web 2.0 data warehouses to assess quality and equity in online learning environments," Educational Researcher, vol. 41, no. 7, pp. 7-15, 2012.

[12] M. Ito, H. Horst, M. Bittanti, danah boyd, B. Herr-Stephenson, P. G. Lange, C. J. Pascoe, and L. Robinson, "Living and learning with new media: Summary of findings from the digital youth project," John D. and Catherine T. MacArthur Foundation Reports on Digital Media and Lerning, Nov. 2008. [Online]. Available: http://www.macfound. org/media/article_pdfs/DML_ETHNOG_WHITEPAPER.PDF

[13] R. Christensen, G. Knezek, and T. Overall, "Transition points for the gender gap in computer enjoyment," Journal of Research on Technology in Education, vol. 38, no. 1, pp. 23-37, 2005.

[14] J. King, T. Bond, and S. Blandford, "An investigation of computer anxiety by gender and grade," Computers in Human Behavior, vol. 18, no. 1, pp. 69-84, Jan. 2002. [Online]. Available: http: //dx.doi.org/10.1016/s0747-5632(01)00030-9

[15] J. J. Ryoo, J. Margolis, C. H. Lee, C. D. M. Sandoval, and J. Goode, "Democratizing computer science knowledge: Transforming the face of computer science through public high school education," Learning, Media and Technology, vol. 38, no. 2, pp. 161-181, Jun. 2013. [Online]. Available: http://dx.doi.org/10.1080/17439884.2013.756514

[16] J. Margolis, J. J. Ryoo, C. D. M. Sandoval, C. Lee, J. Goode, and G. Chapman, "Beyond access: Broadening participation in high school computer science," ACM Inroads, vol. 3, no. 4, pp. 72-78, Dec. 2012.

[17] S. McGee, "Looking beyond academic achievement for inspiring the next generation," Paper presented at the annual meeting of the American Educational Research Association, New York., Mar. 2008, available at http://www.lponline.net/papers.html.

[18] D. W. Rutstein, E. Snow, and M. Bienkowski, "Computational thinking practices: Analyzing and modeling a critical domain in computer science education," http://pact.sri.com/downloads/ Computational-Thinking-Practices1.pdf, Apr. 2014.

[19] J. Goode, J. Margolis, and G. Chapman, "Curriculum is not enough: The educational theory and research foundation of the exploring computer science professional development model," in SIGCSE '14. Association for Computing Machinery, 2014.

[20] R. I. Greenberg and S. McGee, "ECS evaluation survey instruments," http://rig.cs.luc.edu/ rig/ecs/SurveyInstruments.pdf, Oct. 2014, Compilation of multiple surveys: ECS student preSurvey pp. 1-2, ECS student postSurvey pp. 3-4, teacher background suvey pp. 5-11, teacher ECS workshop feedback form pp. 12-13, teacher ECS implementation survey pp. 14-24. 